a product which lost trimethylamine on boiling with alkali and yielded an unsaturated acid, $\mathrm{C}_{16} \mathrm{H}_{14} \mathrm{O}_{4}$, containing only one methoxyl group. On oxidation with potassium permanganate, oxalic acid and $\mathrm{C}_{14} \mathrm{H}_{12} \mathrm{O}_{3}$ were formed; the latter was found to be an aldehyde which on further oxidation yielded an acid $\mathrm{C}_{14} \mathrm{H}_{12} \mathrm{O}_{4}$. Thus methylation shows that desiodothyroxin is almost certainly an amino acid, and that it contains only one phenolic group; the splitting off of oxalic acid suggests the presence of a three-carbon side chain. Now fusion with potash led to the conclusion that two benzene rings are present; if linked through a carbon atom, a ketone should have been formed instead of an aldehyde on oxidation of the methylated product; hence they must be linked either directly or through the oxygen atom, which is still unaccounted for. Considering the latter supposition the more probable, the author proceeded to meet the degradation by synthesis.

The steps in the disintegration by exhaustive methylation and in the subsequent synthesis may be rendered clearer if the following structural formulæ are given :

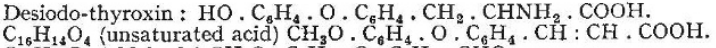
$\mathrm{C}_{14} \mathrm{H}_{12} \mathrm{O}_{3}$ (aldehyde) $\mathrm{CH}_{2} \mathrm{O} . \mathrm{C}_{6} \mathrm{H}_{4} \cdot \mathrm{O}_{6} \cdot \mathrm{C}_{6} \mathrm{H}_{4} . \mathrm{CHO}_{6}$.

$\mathrm{C}_{14} \mathrm{H}_{72} \mathrm{O}$, (saturated $\mathrm{CH}_{3} \mathrm{O} \cdot \mathrm{C}_{6} \mathrm{H}_{4} \cdot \mathrm{O} \cdot \mathrm{C}_{6} \mathrm{H}_{4} \cdot \mathrm{COOH}$

$\mathrm{C}_{13} \mathrm{H}_{12} \mathrm{O}_{2}$ (from potash fusion) $\mathrm{HO} \cdot \mathrm{C}_{6} \mathrm{H}_{4} \cdot \mathrm{O}_{6} \cdot \mathrm{C}_{6} \mathrm{H}_{4} \cdot \mathrm{CH}_{3}$.

The starting-point in the synthesis was parabromanisol, $\mathrm{CH}_{3} \mathrm{O} \cdot \mathrm{C}_{6} \mathrm{H}_{4} \cdot \mathrm{Br}$; on condensation with the potassium salt of paracresol in the presence of copper bronze, 4 ( $4^{\prime}$ methoxyphenoxy) toluene, $\mathrm{CH}_{3} \mathrm{O} \cdot \mathrm{C}_{6} \mathrm{H}_{4} \cdot \mathrm{O} \cdot \mathrm{C}_{6} \mathrm{H}_{4} \cdot \mathrm{CH}_{3}$, was formed. On boiling with hydriodic acid, the compound $\mathrm{C}_{13} \mathrm{H}_{12} \mathrm{O}_{2}$ was produced, whilst on boiling with permanganate the toluene compound was oxidised to the corresponding benzoic acid, $\mathrm{C}_{14} \mathrm{H}_{12} \mathrm{O}_{4}$.

The complete synthesis of desiodo-thyroxin was carried out by a slightly different route; parabromanisol was condensed with potassium phenate to give ( $4^{\prime}$ methoxyphenoxy)-benzene, from which, by the hydrocyanic acid method, the aldehyde $\mathrm{C}_{14} \mathrm{H}_{12} \mathrm{O}_{3}$ was obtained. The latter could be oxidised to the acid $\mathrm{C}_{14} \mathrm{H}_{12} \mathrm{O}_{4}$. From the aldehyde both the acid $\mathrm{C}_{16} \mathrm{H}_{14} \mathrm{O}_{4}$ and desiodo-thyroxin were synthesised; two methods were used in the case of the latter. The aldehyde was condensed with glycine anhydride in the presence of acetic anhydride and sodium acetate; the product on boiling with hydriodic acid and red phosphorus underwent simultaneous reduction, demethylation and hydrolysis, with the production of desiodo-thyroxin. In the alternative method the aldehyde was condensed with hydantoin, which on boiling with the same reagents yielded the desired product.

As regards the position of the iodine atoms in thyroxine, the author considers that it is probable that two are present in each benzene ring, in each case lying on either side of and next to the oxygroups, i.e. in the $3,5,3^{\prime}, 5^{\prime}$ positions. The details of the final synthesis will be awaited with interest.

\title{
Annual Visitation of the National Physical Laboratory, Teddington.
}

$\mathrm{O}^{\mathrm{N}}$ Tuesday, June 22, the General Board of the National Physical Laboratory made its annual visitation of the Laboratory. As in previous years, a large number of members of scientific institutions, technical societies, Government departments, and industrial organisations were also invited to be present. The visitors were received by Sir Ernest Rutherford, president of the Royal Society and chairman of the General Board, and the Director.

The extensive programme of exhibits illustrated well the comprehensive nature of the work which the Laboratory undertakes.

In the I4-foot wind channel a model of the Cierva autogyro, which has aroused so much interest in aeronautical circles, was undergoing test. The model is mounted on three supports forming an inverted pyramid. The vertical forces on the feet of these supports can be measured, enabling the three component forces on the model to be determined, and quantitative data to be obtained for comparison with the conventional type of aeroplane. Another exhibit showed experimental arrangements for the investigation of the spinning characteristics of a model aeroplane. The model under test is mounted on an axis parallel to the wind direction in such a manner that its incidence can be varied. Examination of its behaviour permits the main features of the spinning motion to be studied so that it is possible to indicate what features in design are undesirable from this point of view.

In one of the smaller wind channels experiments were in progress to determine the convective dissipation of heat from the surface of an aerofoil in a wind current. Thin strips of platinum foil cemented to the entire aerofoil and parallel to the span can be heated electrically. Their temperatures can be determined by resistance measurements and equalised by adjustment of the currents traversing them. Measurements of their resistance and of the currents determine the rates of loss of energy from the individual strips.
A new I-foot wind channel has been added to the equipment of the Department. This is intended primarily for the development and calibration of instruments for measuring wind speed and direction.

Among the exhibits of the Metallurgy Department were eight samples of British Standardised Steel, issued jointly by the Iron and Steel Institute and the National Physical Laboratory. These comprised four carbon standards containing respectively 0.10 per cent., 0.27 per cent., 0.65 per cent., and I.09 per cent. of carbon, two sulphur standards containing respectively 0.027 per cent. and $0.07 \mathrm{I}$ per cent. of sulphur, one standard containing phosphorus ( $\mathrm{O} \cdot 029$ per cent.) and one manganese (0.69 per cent.). These standards are prepared from fine millings taken from six-inch bars. Millings taken from the outer layers and the core are rejected, samples of the remainder being subjected to analysis by the Laboratory and various co-operating authorities.

Specimens of pure elements prepared in the Department were also on view. Mention may be made of two of these with which some advance has been made, namely, beryllium and silicon. The former is prepared by the electrolysis of a mixture of the fluorides of beryllium, sodium, and barium, a rotating cathode being used. This is slowly withdrawn at a predetermined rate with the pure metal adhering. Special precautions are taken to prevent contamination of the metal by enclosing the salts in special crucibles. Specimens of these made of magnesia and alumina were shown in the foundry. For work on the constitution of silicon-aluminium alloys and on age hardening in aluminium alloys, very pure silicon is required. Samples were shown of 99.8 per cent. purity. Another exhibit illustrated the microscopic examination of metals usually liquid at ordinary temperatures. Such materials as are used in dental practice are included in this category. By surrounding them with a freezing mixture of carbon dioxide snow and acetone, it is possible to polish the surface to the degree requisite for microscopic examination. 
In the William Froude National Tank a model selfpropelled single screw vessel was shown under test. Simultaneous measurements were recorded of propeller thrust, shaft revolution, and distance travelled. These enable the propeller torque and power expended under varying conditions produced in the tank to be compared, and permit the losses due to the propeller, hull, and sea conditions to be apportioned.

In the Engineering Department research was in progress on the mechanical properties of metals and alloys for use at high temperatures, such as are experienced in modern steam engines and gas engines. At high temperatures metals generally used undergo continuous creep under steady loads, lower than those obtained in normal tensile stress determinations. Experimental work is being done to determine the rate of creep of such materials at various temperatures. For this purpose the test pieces are surrounded by an electric furnace maintained at the required temperature, a steady load being applied by a lever system. Any elongation can be measured by means of micrometers attached to the apparatus. Fatigue can also be studied in a special machine in which the stresses are produced by means of an alternating current, the specimen being heated in position by heating coils.

An investigation was also being carried out on the impact strength of chains. Normally chains are annealed periodically in order to counteract any tendency to embrittlement and the tests were designed with the view of determining the effect of this annealing on the strength of the chain. Of interest also was a trough in which the production of capillary and gravitational waves in water by means of a current of air acting on the surface was demonstrated.

In the Metrology Department, apparatus was shown for the absolute measurement of end gauges up to 4 in. in length. The gauge is converted into a Fabry-Perot étalon by means of two optical flats wrung on to its end faces, the flats having portions extending beyond the edges of the gauge, these portions being semi-silvered on their inside faces. When placed in a convergent beam of monochromatic light, interference fringes in the form of concentric circles are produced. Measurements of the angular diameter of such fringes in various monochromatic radiations enable the optical length between the two semi-silvered surfaces to be determined. The semisilvered flats are produced at the Laboratory by the method of cathodic deposition, the glass to be silvered being placed near a silver cathode in a vacuum chamber. The apparatus employed for this purpose was on view. A monochromator, designed and constructed for use in connexion with interference measurements, was also exhibited.

In the workshop was apparatus for the study of the deformation of pivots under load. The pivot to be tested is mounted so that its point can be brought into contact with a flat sapphire by a balance arm. An image of the pivot is projected on to a screen and measurements made without and with a load in the balance pan, the magnification being 200 times.

A very large number of exhibits was shown in the Physics Department. Among these was apparatus for the determination of the thermal conductivities of materials at high temperatures by the measurement of the radial gradient in an electrically heated rod of the material.

A resistance bridge for platinum thermometry, made to the design of Mr. F. E. Smith and capable of measuring temperatures to $0^{\circ} \mathrm{ooI}^{\circ} \mathrm{C}$., was exhibited. To obtain this accuracy special precautions are taken to control not only the temperature of the oil tank in which the coils are immersed but also the humidity of the oil, since this latter factor affects the resistance of the coils.

A new apparatus has also been designed for the purpose of measuring the change of length of ' constant length' type bubbles in spirit-level tubes under extremes of atmospheric temperatures likely to be encountered in surveying practice, namely, $-18^{\circ} \mathrm{C}$ to $55^{\circ} \mathrm{C}$. For this purpose an optical device is used by means of which both ends of the bubble are viewed simultaneously and brought into coincidence, the length being determined in one observation. In this apparatus special attention is given to the geometrical design of the moving parts and to the fine adjustments.

A variety of problems connected with refrigeration were being investigated for the Engineering Committee of the Food Investigation Board. These included apparatus for measuring the heat evolution in fruit by a process which may be compared with that of respiration in animals. In this apparatus a differential arrangement is used in which the heat evolved by apples is balanced by that from an electrical supply. For comparing the relative values of the resistance to indentations of specimens of cork slab and other heat-insulating materials, an apparatus has been constructed in which the depth of penetration of a steel ball about 3 in. in diameter is measured by a dial indicator.

Several forms of the Ewing ball and tube flow-meter were shown. In this instrument a glass or metal sphere is placed in a glass tube of conical bore and the displacement of the ball under the action of the flow of liquid is observed.

In the Optics Section was shown the "Vector" colorimeter, an instrument which enables colour to be specified by measurements involving colour-matching only. In use the colour to be tested is matched first against a mixture of extreme red with some suitable monochromatic light and then against a mixture of spectrum blue with another suitable monochromatic constituent. These matches determine two vectors on a colour chart and the intersection of these determines the unknown colour. Other apparatus included a flicker photometer for heterochromatic photometry and a spectrophotometer not involving polarising constituents.

In the Radiology Section was shown a new X-ray tube with detachable electrodes. In this tube, porcelain is substituted for the glass and the electrodes are fitted with rubber washers. The arrangement allows the tube to be dismantled for cleaning or other purposes and reassembled in a very short time. Apparatus for the study of the wave-forms of high tension generators by oscillographic methods was also shown working. By means of optical trains the wave-forms to be examined, together with a time curve from a tuning fork, are simultaneously recorded on a photographic plate.

In the Electrotechnics Department was shown a method of measuring high voltage dielectric loss. The Schering bridge is a capacity bridge specially suited for measurements of power losses at high voltages and small power factors; it ensures safety to the observer together with the accuracy attainable by other methods. Thus the method is applicable to the study of small phase defects in condensers. Power factors of I per cent. can be measured correct to I per cent. The dielectric loss in a cable at 20,000 volts was being investigated; in this application the vibration galvanometer and bridge operating arms need never be more than 2 volts above earth potential.

Research work was being carried out in the Direct Current Section on the earthing of electric circuits. Various forms of earthing electrodes suitably spaced are sunk in the ground, and their resistances determined

NO. 2958, VOL. I I 8 ] 
and compared under varying conditions of soil humidity.

In the Photometry Division a large integrating sphere Io feet in diameter, constructed by the Metrology Department, was shown in use. It is intended primarily for the photometry of large illumination fittings. Apparatus has also been installed for the purpose of measuring candle-power by means of photo-electric cells. Light from the lamp under test falls on a rubidium cell mounted at one end of a photometer bench. A lamp mounted in a whitened cube, in the floor of which is a second cell screened from the direct light of the lamp, provides a suitable source for comparison. The cells, connected in series, are arranged to form part of a Wheatstone bridge and their currents are balanced by suitable adjustment of the illumination. In the illumination building experimental arrangements were shown for determining the daylight illumination in large or small rooms by means of models. Such information indicates the probable behaviour of their full scale prototypes with regard to daylight and is thus of value in architecture.

In the Wireless Division experience has shown the importance of complete screening of local oscillators and receivers from local electrical disturbances. Several pieces of apparatus, so protected, and including oscillators and receiving apparatus, a variometer and a model frame aerial, were exhibited. The knowledge has been used in the case of amplification tests on valve amplifiers. The amplifier under test and the local oscillator are both carefully protected, the former being placed in a specially screened room. Experimental work in connexion with short wave transmission is also being developed and various transmitting and receiving circuits were on view.

In the Electrical Measurements Department, in addition to the usual equipment, were various quartz piezo-electric resonators for use as radio frequency standards. These, on account of their constant frequency, are very suitable for the control of oscillators. One such oscillator with amplifying valves designed to produce radio frequency oscillations of great power and extremely constant frequency has been installed.

$$
\text { L. J. C. }
$$

\section{University and Educational Intelligence.}

Birmingham.--The annual degree congregation was held on July 3. There were 6 successful candidates for the degree of Ph.D., 9 for M.Sc., 77 for the degree of B.Sc. with Honours, 48 for the ordinary B.Sc., and 24 for M.B., Ch.B. The degree of Doctor of Medicine was conferred on Gladys Mary Evans and Mr. Victor Goode Williams.

Dr. Laurence Ball, assistant to the chair of medicine and physician to the Queen's Hospital, has been appointed joint professor of medicine to fill the vacancy caused by the resignation of Prof. Kauffmann.

BRISTOL.-Sir George Wills, Pro-Chancellor and chairman of the Council of the University, has given $25,000 l$, to be used with the IIO,000l. which he presented two years ago, for the erection of a residential hall for students.

CAMBRIDGE.--The Mayhew Prize in applied mathematics has been divided between J. A. Gaunt, Trinity College, and A. H. Wilson, Emmanuel College. The Rex Moir Prize in mechanical sciences has been awarded to H. L. Cox, Emmanuel College, and the John Bernard Seely Prize in aeronautics to R. E. Stevenson, St. John's College.

Durham.-Dr. Arthur Holmes, hitherto reader in geology, has recently been made professor of geology at Durham. Two new lectureships have been filled by the appointment of Dr. R. K. Schofield (physics), and of Dr. G. H. Christie (chemistry).

LoNDON.-A University post-graduate travelling studentship of the value of $275 \mathrm{l}$. has been awarded to Miss C. L. T. Lucas. Miss Lucas obtained the B.Sc. with honours in zoology as an internal student of Bedford College in 1923, and has worked since at the London School of Tropical Medicine. She proposes to carry out research on Amœbæ living in insects, chiefly at the Johns Hopkins University, Baltimore.

ST. ANDREWS.-The degree of D.Sc. in engineering has been conferred upon Mr. William John Walker for a thesis entitled "Developments of Engineering Thermodynamics. Analysis for Variable Specific Heat Conditions." Dr. Walker has resigned the post of lecturer in mechanical engineering and machine design held by him in University College, Dundee, having been appointed professor of mechanical engineering at the University of the Witwatersrand, Johannesburg.

Prof. A. E. Morgan, professor of English Ianguage and literature in the University of Sheffield, has been appointed principal of University College, Hull.

DR. W. E. CuRTIs has been appointed professor of physics and director of the Physics Department at Armstrong College, Newcastle-on-Tyne, in succession to Prof. Henry Stroud, who retires at the end of the present session. Dr. Curtis, who is at present reader in physics in King's College, London, was educated at the Imperial College of Science and Technology, London, and was for a time lecturer in physics in the University of Sheffield. $\mathrm{He}$ is the author of important papers on spectroscopy.

THE third Congress of the Universities of the Empire will be in session at Cambridge on July I3-16. The subjects for discussion and the names of the chairmen are as follows: "The State and the University," Lord Balfour; "The Desirability of establishing in London a School of Advanced Legal Studies," the Lord High Chancellor; "Co-operation in Research throughout the Empire," Lord Londonderry; "Mutual Recognition of Examinations and of Time spent in Study Elsewhere," Sir Matthew Nathan; "The Desirability of making Provision for the Physical Welfare and Training of Students and the Organisation of Athletics with a View to securing more general Participation," the Duke of Devonshire; "The Actual Working of the Ph.D. Scheme," Viscount Cecil of Chelwood; "The Desirability of Articulating other Pension Schemes with the Fiederated Superannuation System of Great Britain and Ireland," Lord Haldane. Among the invited speakers on "Co-operation in Research" are Sir Thomas Holland, Sir John B. Farmer, Sir Arthur Shipley, and Dr. Andrew Balfour; on the Ph.D. scheme, Mr. R. A. Priestley, Prof. Wenley, of the American University Union, Prof. Dobson of Bristol, and Prof. H. P. Newton, of King's College, London. Representatives of India, Australia and Canada, as well as Sir Alfred Hopkinson and Sir Theodore Morison, are among those who have promised to contribute to the discussion on "The State and the University." The sessions at Cambridge will be preceded by series of visits by delegates from overseas to all the other universities of Great Britain and Ireland. On July is there will be a Government luncheon in honour of the delegates, at which Lord Peel will preside, and in the evening they will have an opportunity of meeting the members of the second Anglo-American conference of professors and teachers of history at a reception given by the University of London. 